\title{
INDICATIONS AND OUTCOMES OF INTRAVITREAL TRIAMCINOLONE ACETONIDE INJECTION IN MACULAR OEDEMA
}

\author{
Smita Anand ${ }^{1}$, Rajiv Kumar ${ }^{2}$ \\ ${ }^{1}$ Senior Resident, Department of Ophthalmology, Rajendra Institute of Medical Sciences, Ranchi. \\ 2 Professor, Department of Ophthalmology, Rajendra Institute of Medical Sciences, Ranchi.
}

\begin{abstract}
To determine the indications, complications, and outcomes of intravitreal triamcinolone acetonide (IVitTA) injection in macular oedema.

METHODS

This retrospective study included 105 eyes of 81 patients who received 4 mg IVitTA for treatment of macular oedema due to different aetiologies between May 2011-October 2012. Recorded were demographic data, best corrected visual acuity, intraocular pressure (IOP), degree of cataract if any, macular thickness (By optical coherence tomography) complications and improvement in visual acuity and macular oedema.
\end{abstract}

\section{RESULTS}

Short-term improvement in visual acuity and macular thickness were in 50\% patients and long-term outcomes were less promising. Main complications were cataract (61\%), increase in IOP (31\%).

\section{CONCLUSION}

IVitTA remains a promising therapy for patients with macular oedema of different aetiologies refractory to other modalities of treatment at least in short term. It seems relatively safe, but not without complications.

\section{KEYWORDS}

IVitTA-Intravitreal Triamcinolone Acetonide, Macular Oedema, RVO-Retinal Vein Occlusion, DME-Diabetic Macular Oedema.

HOW TO CITE THIS ARTICLE: Anand S, Kumar R. Indications and outcomes of intravitreal triamcinolone acetonide injection in macular oedema. J. Evolution Med. Dent. Sci. 2016;5(56):3836-3840, DOI: 10.14260/jemds/2016/878

\section{INTRODUCTION}

Macular oedema is a common complication of diabetic retinopathy, retinal venous occlusions, intraocular surgery, and variety of retinal diseases. It is a major cause for visual loss particularly in its diffuse or chronic form. The failure of laser to improve vision in a substantial subgroup of patients with macular oedema in the above settings has created interest in other treatment methods. One such treatment, promoted in the late 1990's, is intravitreal injection of steroids namely intravitreal triamcinolone acetonide injection (IVitTA). We retrospectively reviewed the charts of 105 eyes of 81 patients ( 61 male and 20 female) who received $4 \mathrm{mg}$ of IVitTA for the treatment of macular oedema secondary to diabetes, retinal vein occlusion, or postsurgical macular oedema between May 2011 and October 2012 in Regional Institute of Ophthalmology, RIMS, Ranchi.

\section{PATIENTS AND METHODS}

All of the patients were fully informed about the new and experimental character of the treatment. Patients were included in this retrospective review if they met the following Inclusion Criteria.

Financial or Other, Competing Interest: None.

Submission 02-04-2016, Peer Review 30-05-2016,

Acceptance 06-06-2016, Published 13-07-2016.

Corresponding Author:

Dr. Smita Anand,

Senior Resident,

Department of Ophthalmology,

Rajendra Institute of Medical Sciences,

Ranchi-834009, Jharkhand.

E-mail: smita.anand2001@gmail.com

DOI: $10.14260 /$ jemds $/ 2016 / 878$
1. Had macular oedema due to diabetic retinopathy, retinal venous occlusion, or postsurgical macular oedema (Irvine-Gass syndrome). Other causes of macular oedema were excluded.

2. Received IVitTA injection of $4 \mathrm{mg}$ in $0.1 \mathrm{~mL}$. Higher doses of TA were excluded.

3. Received the intravitreal injection in a semi-standard protocol, which included an anterior chamber paracentesis immediately post injection. Cases without paracentesis those prepared with prior massage or those receiving routine acetazolamide or other IOP lowering agents following injection were excluded in an aim for consistency for the review.

4. Were followed for a minimum of 6 months.

Included in the baseline data entry for all cases were: Patient's age, sex, Baseline Snellen's best corrected visual acuity, baseline intraocular pressure (IOP), degree of cataract if any, type of macular oedema as clinically documented in the records, optical coherence tomography (OCT) when available including: central macular thickness and pattern of macular oedema. The procedure for intravitreal triamcinolone injection was standard. Triamcinolone acetonide $(0.1 \mathrm{~mL}$ of $40 \mathrm{mg} / \mathrm{mL}$; Tricort 40, Cadila Pharmaceuticals) was injected into the mid-vitreous cavity using a 27 -gauge needle on a 1$\mathrm{mL}$ tuberculin syringe using 30-gauge needle followed. After injection, perfusion of central retinal artery was noted. Injected eyes were patched for a few hours and patients were prescribed topical antibiotic drops for 5 to 7 days.

Patients were instructed to monitor their symptoms and report to the hospital in case of unusual ocular redness or pain. 
Most cases were additionally re-examined at 1 day after injection to rule out infection or elevated IOP. Follow up data entry for all patients included the results of the examinations at the $3,6,12,15$ months following injection whenever available. Collected data included: best corrected Snellen's visual acuity, IOP, cataract progression, the presence and type of macular oedema as clinically documented, OCT of the macula (Whenever available) including: central macular thickness and pattern of macular oedema, and the presence and management of any complications.

\section{RESULTS}

For the results analysis, the following methodology was used: A-Eyes were grouped into 3 groups:

Group 1: Eyes with diabetic macular oedema,

Group 2: Eyes with retinal venous occlusion,

Group 3: Eyes with postsurgical macular oedema.

\section{B-Results of changes in Visual Acuity were defined as:}

1. Improved: If VA increased by 2 lines or more,

2. Unchanged: If VA remained the same or within 1 line from baseline.

3. Worsened: If VA was reduced by 2 lines or more.

Eyes were considered to have increased intraocular pressures if post injection IOP was equal to or greater than 22 mmHg after triamcinolone injection and/or antiglaucoma medications were used to keep IOP under $21 \mathrm{mmHg}$. To test for statistical significance analysis, we used to compare data using Analysis of Variance (ANOVA) method. A P value of less than 0.05 was considered significant.

In this study, we included 105 eyes of 81 patients. 61 were males (58.5\%) and 20 females (41.5\%). The mean age was $62.5 \pm 9.24$ years (Range 35 to 90 years).

87 eyes $(82.85 \%)$ had persistent clinically significant diabetic macular oedema (CSME) of those, 56 eyes (64.36\%) had non-proliferative diabetic retinopathy (NPDR) and 31 eyes (35.64\%) had proliferative diabetic retinopathy (PDR).

14 eyes had macular oedema secondary to retinal venous occlusion (RVO) (13.33\%). Of those, 4 eyes $(28.57 \%)$ had ischemic CRVO and 6 (42.85\%) had macular ischemia evidenced by fundus fluorescein angiography ( 5 eyes with CRVO and 1 with BRVO).

Four eyes (3.80\%) had postsurgical macular oedema all following cataract surgery.

Of the entire group of patients, 32 eyes (30.47\%) were pseudophakic and 7 eyes $(6.66 \%)$ had glaucoma before the injection. Hypertension was found in 40 patients $(38.09 \%)$, hyperlipidemia in 7 patients $(6.66 \%)$, renal failure in 5 patients $(4.76 \%)$, and ischemic heart disease in 6 patients (5.71\%). The mean best corrected visual acuity (BCVA) (logMAR) for the entire group of eyes was $0.90 \pm 0.18$ [Snellen equivalent 20/160] (Median 20/200, range 20/25 to hand movement).

\section{Group 1: Diabetic Macular Oedema}

87 eyes had diabetic macular oedema The baseline mean BCVA (logMAR) was $0.90 \pm 0.18$ [Snellen equivalent 20/160] (Median 20/200, range 20/25 to hand motion). 69 eyes were available at the 3 months follow up, 39 eyes were seen at 6 months, 54 were seen at one year, and 73 were seen at 15 months. By the last follow up at 15 months, 10 eyes out of 27 $(37.03 \%)$ had improved VA, 8 eyes $(29.62 \%)$ had unchanged
VA, and 9 eyes (33.33\%) had worse VA as compared to baseline.

\section{Group 2: Macular Oedema in Retinal Venous Occlusion}

14 eyes had macular oedema secondary to retinal venous occlusion. The mean baseline BCVA (logMAR) was $1.18 \pm 0.10$ [Snellen equivalent 20/300] (Median 20/400, range 20/80 to hand movement).

Data was available at 3 months follow up in 12 eyes. At this date and following a single IVitTA injection, 6 eyes out of $12(50 \%)$ had improved VA by 2 Snellen lines or more, 5 eyes (41.66\%) had unchanged VA and 1 eye $(4.76 \%)$ had worse VA compared to baseline. 7 of the 12 eyes were available for examination at 6 months. At 6 months, 4 out of 7 eyes $(57.13 \%)$ had VA improvement compared to baseline and 3 eyes (41.66\%) had unchanged VA compared to baseline.

For further analysis, for those eyes that had initial improvement at 3 and 6 months, 4 out of $8(50 \%)$ maintained VA improvement at 1 year and only 2 out of $7(28.57 \%)$ maintained VA improvement at last follow up at 15 months.

\section{Visual Acuity Results in Postsurgical Macular Oedema}

Four eyes had postsurgical macular oedema. The mean BCVA (logMAR) for this group was $0.80 \pm 0.10$ [Snellen equivalent 20/125] (median 20/125, range 20/60 to 20/400). Data was available at 3 months in 3 eyes. At 3 months follow up and when compared to baseline, 1 eyes out of 3 (33.33\%) had improved VA by 2 Snellen lines or more and 2 eyes (66.66\%) had unchanged VA as compared to baseline. 4 eyes were available for examination at 6 months follow up, 2 out of 4 eyes (50\%) had VA improvement, one eye $(25 \%)$ had unchanged VA, and one eye (25\%) had worse VA as compared to baseline. By the last follow up at 15 months, 2 out of 4 eyes $(50 \%)$ had unchanged VA and 2 eyes (50\%) had worse VA as compared to baseline.

\section{Group 3: Postsurgical Macular Oedema}

Statistical analysis for eyes with postsurgical macular oedema that received IVitTA showed that the difference in mean BCVA ( $\log$ MAR) between baseline and follow ups at 3, 6, 12, and 15 months, was statistically not significant ( $\mathrm{p}=0.185$, ANOVA).

When studying the correlation between BCVA and OCT thickness in eyes with diabetic macular oedema, the correlation was statistically not significant at 3,6 , and 15 months, $(\mathrm{P}=0.237),(\mathrm{P}=0.102)$, and $(\mathrm{P}=0.637)$ respectively.

Similarly, the correlation between BCVA and OCT thickness in the retinal vein occlusion group, was also not statistically significant at $3,6,12$, and 15 months, $(\mathrm{P}=0.437)$, $(\mathrm{P}=0.341),(\mathrm{P}=0.326)$, and $(\mathrm{P}=0.55)$ respectively.

\section{COMPLICATIONS}

\section{Increased Intraocular Pressure}

For analysis of IOP, the study eyes were divided into two groups: Non-vein occlusion group (84 eyes) and vein occlusion group (14 eyes). Seven eyes with previous history of glaucoma were excluded from this analysis.

\section{In the Non-Vein Occlusion Group}

At the 3-months follow up, the number of eyes that had elevated IOP (>22 mmHg) was 21 out of 67 (31.34\%). The mean baseline IOP \pm SD increased from $15.58 \pm 3.08 \mathrm{mmHg}$ (Median 15, range $9-25 \mathrm{mmHg}$ ) to $19.48 \pm 4.77 \mathrm{mmHg}$ (Median 19, range 9-35 $\mathrm{mmHg}$ ), which was statistically significant $(\mathrm{p}<0.001)$. 
Only 2 eyes of 60 (3.33\%) continued to exhibit high IOP despite antiglaucoma medications, while 10 eyes (9.01\%) were receiving antiglaucoma medications, but had normal IOP. The mean IOP at the last follow up continued to be higher compared to baseline $(16.25 \pm 3.59 \mathrm{mmHg}$; median 16 , range 9-30 $\mathrm{mmHg}$ ), but the difference was not statistically significant $(\mathrm{p}<0.089)$

\section{In the vein occlusion group}

At the 3-months follow up, the number of eyes that had elevated IOP ( $>22 \mathrm{mmHg}$ ) was 4 out of $11(36.36 \%)$. The mean baseline IOP \pm SD increased from $15.82 \pm 3.52 \mathrm{mmHg}$ (Median 16, range $10-22 \mathrm{mmHg}$ ) to $21.83 \pm 7.86 \mathrm{mmHg}$ (Median 18, range 9-41 $\mathrm{mmHg}$ ), which was statistically significant $(\mathrm{p}<0.001)$.

Intraocular pressures continued to be elevated at the second follow up at 6 months with a mean of $17.83 \pm 4.58$ $\mathrm{mmHg}$, but the difference was not statistically significant $(\mathrm{p}=0.15)$.

When considering all eyes, the average duration of elevated IOP was 6.8 months. Glaucoma surgery was needed in 2 eyes where the high IOP was considered to be directly related to the IVitTA injection. Both cases were in the nonvein occlusion group.

\section{Cataract Progression}

73 eyes had documentation regarding the crystalline lens available in the records. Cataract progression was noticed in 45 eyes of $73(61.64 \%)$ by the last follow up. In 23 of these eyes $(31.5 \%)$, the cataract was visually significant and the patients underwent cataract surgery.

\section{Endophthalmitis}

A classic picture of endophthalmitis developed one day post INVIT TA injection in a one-eyed diabetic patient who was receiving the injection for the treatment of macular oedema secondary to central vein occlusion. Pre-injection VA was counting fingers. The next day, VA dropped to light perception with no ocular pain, mild conjunctival congestion, hypopyon, and loss of red reflex. Immediate intravitreal antibiotics injection permitted to effectively clear the media and restore VA to counting fingers again. The vitreous specimens were cultures negative. Based on these findings, this case most probably exhibited a sterile endophthalmitis $0.51 \%$ in this series).

None of the patients in this series developed infectious endophthalmitis.

\section{Other Complications}

Many complications were encountered in this retrospective study; however, most of them were attributed to the original disease and not to the INVIT TA injection. Among these complications were:

1. Vitreous haemorrhage, which developed in 14 eyes, reported several months after the injections and attributed to proliferative diabetic retinopathy.

2. Tractional retinal detachment secondary to proliferative diabetic retinopathy developed in two eyes. Both underwent vitrectomy with membrane peeling.

3. Neovascular glaucoma related to proliferative diabetic retinopathy developed in 4 eyes 5 to 15 months after injection.

\section{DISCUSSION}

The studies on diabetic macular oedema have suggested that intravitreal triamcinolone acetonide may be useful to increase visual acuity in patients with diffuse diabetic macular oedema. $(1,2,3,4,5)$ In our study, the early visual acuity results were encouraging as injected eyes showed significantly better visual acuity levels at 3 months (47.65\%) and 6 months (46.57\%) compared to baseline. On the other hand, the late visual results at 15 months were less promising. Only $36.9 \%$ of eyes maintained some VA improvement and there was no significant difference between baseline VA and late VA levels. These findings are in agreement with many reported series. $(1-5,6,7)$

Our results showed that triamcinolone acetonide improves VA significantly up to 6 months after injection $(\mathrm{P}=0.006)$. Mean BCVA improved from $20 / 160$ at baseline to $20 / 100$ at 6 months. Furthermore, at the last follow up, although statistically not significant $(\mathrm{P}=0.12)$ the mean BCVA continued to be better than baseline (20/125 vs 20/160). A proportion of eyes $(26.4 \%$ of those who had initial improvement) continued to have better VA at 15 months if IVitTA injection was followed by further laser treatment (Focal or grid), which suggest that IVitTA may enhance and strengthen the effect of laser treatment when both modalities are combined $(6,7,8)$. This finding was also shown by Karderli et al(8) who evaluated in a prospective interventional and comparative study 16 eyes that received IVitTA followed by macular focal and grid laser treatment after one month. Improvements in vision were significant and maintained at 9 months post injection as compared to the control group who had only laser treatment without IVitTA.

Central macular thickness measured by OCT showed significant improvement 3 months $75.43 \%$ and at 6 months $68.42 \%$ after injection compared to baseline. By 15 months, however, only $44.11 \%$ showed improvement in central macular thickness compared to baseline. We found no significant correlation however between VA improvements and reduction in OCT thickness. This is not surprising since numerous other factors affect vision including macular ischemia in diabetes and retinal venous occlusion, macular haemorrhage, degenerative macular changes as a result of chronicity of macular oedema, progression of cataract to name a few. Intravitreal triamcinolone treatment has exhibited encouraging results for patients with vascular occlusive diseases and macular oedema.(9-14,15,16) Similar results were found in our study in eyes with macular oedema secondary to retinal venous occlusion, which showed improvement in mean BCVA from 20/300 at baseline to $20 / 125$ at 15 months ( $\mathrm{p}=0.03$ ). At 15 months, $50 \%$ of eyes had improved VA when compared to baseline. However, we must caution that the retinal venous occlusion group had, in general, a better follow up rate than the diabetic macular oedema group, and a significant number of eyes with retinal venous occlusions underwent repeated injections (30.77\%) compared to only $19.75 \%$ of the diabetic eyes. This may explain the maintained long-term visual improvement.

The results in eyes with retinal venous occlusion and macular ischemia evidenced by fundus fluorescein angiography were disappointing as only $33.33 \%$ of eyes improved at 3 months and $40 \%$ by 15 months. The poor response to the injection is most likely related to macular ischemia. 
Similar results were also shown by Cekic et al(17) who found that eyes with ischemic CRVO or concurrent diabetes are less likely to have visual improvement after IVitTA injection.

Our results in the group of postsurgical macular oedema were not encouraging as the mean final VA was worse 20/160 at 15 months compared with 20/125 at baseline. Although, mean VA originally improved to $20 / 50$ in the 1 st follow up at 3 months it failed to reach statistically significant difference $(p=0.07)$ most likely because of small sample size. Although, VA has been reported to improve initially in eyes with postsurgical macular oedema, the need for reinjection is reported to be as high as $100 \%$ and the duration of effect of IVitTA very short (8-12 weeks only).(18,19,20)

The potential complications of intravitreal steroids may be injection related or from the effect of corticosteroid suspension including IOP elevation, progression of cataract, retinal breaks, retinal and choroidal detachment, vitreous haemorrhage, and infectious and non-infectious endophthalmitis. $(3,15,21,22)$

The main side effect of intravitreal triamcinolone acetonide observed in the present study was an elevation of intraocular pressure (31.34\%). Jonas et al found IOP elevation of $>21 \mathrm{mmHg}$ in $50 \%$ of 71 eyes treated with IVitTA. The slightly higher rate of steroid response seen in the study by Jonas et al as compared with $31.34 \%$ seen in the current study may be due to their higher dose of IVitTA ( $25 \mathrm{mg}$ vs. 4 mg used in our study). Moreover, the difference between baseline IOP and last follow up IOP was statistically not significant $(\mathrm{p}=0.089)$.

Vitrectomy with internal limiting membrane peeling and gas injection. Cataract progression is well known complication of IVTA. In our series, cataract progression was documented to be about $61.64 \%$ at any time of follow up. This seems to be higher than what is mentioned in the literature ( $14 \%$ by Jonas at one year, $28 \%$ by Gillies and $50 \%$ by Cekic), perhaps because of older age in our patients and the longer follow up period in our study. However, only $31.5 \%$ of eyes needed cataract surgery. Endophthalmitis is a very serious complication after IVitTA injection, which may be infectious or non-infectious in origin.

Despite that, this study has a large number of eyes treated with IVitTA and up to 15 months' follow up, it has many limitations not only its retrospective non-randomized nature and the lack of a control group, but also the inconsistent availability of OCT in some visits and most importantly by the unavailability of a large proportion of patients at later follow ups. Although, all patients were observed for at least 6 months, only $65.71 \%$ of eyes were evaluated at 15 months. Furthermore, retreatment as well as cataract surgery were not standardized and were at the discretion of the clinician.

In conclusion, IVTA remains a promising therapy for patients with macular oedema of different aetiologies refractory to other modalities of treatment at least in short terms. It definitely has a role in facilitating and perhaps rendering more effective established treatments such as laser photocoagulation. It seems relatively safe, but not without complications.

The high incidence of IOP elevations and cataract formation limits its repeated use, although the IOP elevation seems to be temporary and to an extent easily controlled.

\section{REFERENCES}

1. Chieh JJ, Roth DB, Liu M, et al. Intravitreal triamcinolone acetonide for diabetic macular oedema. Retina 2005;25(7):828-34.

2. Jonas JB, Sofker A. Intraocular injection of crystalline cortisone as adjunctive treatment of diabetic macular oedema. Am J Ophthalmol 2001;132(3):425-7.

3. Jonas JB, Kreissig I, Sofker A, et al. Intravitreal injection of triamcinolone for diffuse diabetic macular oedema. Arch Ophthalmol 2003;121(1):57-61.

4. Martidis A, Duker JS, Greenberg PB, et al. Intravitreal triamcinolone for refractory diabetic macular oedema. Ophthalmology 2002;109(5):920-7.

5. Massin P, Audren F, Haouchine B, et al. Intravitreal triamcinolone for the treatment of diffuse diabetic macular oedema: preliminary results of a prospective controlled trial. Ophthalmology 2004;111(2):218-24.

6. Patelli F, Fasolino G, Radice P, et al. Time course in retinal thickness and visual acuity after intravitreal triamcinolone acetonide for diffuse diabetic macular oedema with and without previous macular laser treatment. Retina 2005;25(7):840-5.

7. Lam DSC, Chan CKM, Mohamed S, et al. A prospective randomized trial of different doses of intravitreal triamcinolone acetonide for treatment of diabetic macular oedema. Br J Ophtalmol 2006;1:136-40.

8. Karderli B, Avei R, Gelisken 0 , et al. Intravitreal triamcinolone as an adjunct in the treatment of concomitant proliferative diabetic retinopathy and diffuse diabetic macular oedema. Int Ophthalmol 2005;26(6):207-14.

9. Greenberg PB, Martidis A, Rogers AH, et al. Intravitreal triamcinolone acetonide for macular oedema due to central retinal vein occlusion. $\mathrm{Br} \mathrm{J}$ Ophthalmol 2002;86(2):247-8.

10. Jonas JB, Kreissig I, Degenring RF. Intravitreal triamcinolone acetonide as treatment of macular oedema in central retinal vein occlusion. Graefes Arch Clin Exp Ophthalmol 2002;240(9):782-3.

11. Park $\mathrm{CH}$, Jaffe GJ, Fekrat S. Intravitreal triamcinolone acetonide in eyes with cystoid macular oedema associated with central retinal vein occlusion. Am J Ophthalmol 2003;136(3):419-25.

12. Ip MS, Gottlieb JL, Kahana A, et al. Intravitreal triamcinolone for the treatment of macular oedema associated with central retinal vein occlusion. Arch Ophthalmol 2004;122(8):1131-6.

13. Bashshur ZF, Ma'luf RN, Allam $S$, et al. Intravitreal triamcinolone for the management of macular oedema due to non-ischemic central retinal vein occlusion. Arch Ophthalmol 2004;122(8):1137-40.

14. Karacorlu M, Ozdemir H, Karacorlu S. Intravitreal triamcinolone acetonide for the treatment of central retinal vein occlusion in young patients. Retina 2004;24(2):324-7.

15. Degenring RF, Kamppeter B, Kreissig I, et al. Morphological and functional changes after intravitreal triamcinolone acetonide for retinal vein occlusion. Acta Ophthalmol Scand 2003;81(4):399-401. 
16. Chen SDM, Lochhead J, Patel CK, et al. Intravitreal triamcinolone acetonide for ischaemic macular oedema caused by branched retinal vein occlusion. $\mathrm{Br} \mathrm{J}$ Ophthalmol 2004;88(1):154-5.

17. Cekic 0 , Chang $S$, Tseng JJ, et al. Intravitreal triamcinolone acetonide for treatment of macular oedema associated with central retinal vein occlusion and hemiretinal vein occlusion. Retina 2005;25(7):846-50.

18. Conway MD, Canakis C, Li vir-Rallatos C, et al. Intravitreal triamcinolone acetonide for refractory chronic pseudophakic cystoid macular oedema. J Cataract Refract Surg 2003;29(1):27-33.
19. Benhamou N, Massin P, Haochine B, et al. Intravitreal triamcinolone acetonide for refractory pseudophakic macular oedema. Am J Oplathalmol 2003;135(2):246-9.

20. Jonas JB, Degenring RF, Kamppeter BA, et al. Duration of the effect of intravitreal triamcinolone acetonide as treatment of diffuse diabetic macular oedema. Am J OphthalmoI 2004;138(1):158-60.

21. Moshfeghi DM, Kaiser PK, Scott IU, et al. Acute endophthalmitis following intravitreal triamcinolone acetonide injection. Am J Ophthalmol 2003;136(5):791-6.

22. Jonas JB, Kreissig I, Degenring R. Intraocular pressure after intravitreal triamcinolone acetonide injection. $\mathrm{Br} \mathrm{J}$ Ophthalmol 2003;87(1):24-7. 